\title{
Recombinations defining centromeric and telomeric borders for the hereditary haemochromatosis locus
}

\author{
R S Ajioka, P Yu, J R Gruen, C Q Edwards, L M Griffen, J P Kushner
}

Division of Hematology/Oncology, University of Utah

Health Sciences

Center,

50 N Medical Drive, Salt Lake City,

Utah 84132, USA

R S Ajioka

$\mathrm{P}$ Yu

C Q Edwards

L M Griffen

J P Kushner

Department of

Pediatrics,

Yale University

School of Medicine,

New Haven,

CT, USA

J R Gruen

Correspondence to: Dr Ajioka.

Received 12 April 1996 Revised version accepted for publication

for publication

\begin{abstract}
Hereditary haemochromatosis (HFE) is a common inherited disorder, affecting approximately five per thousand white people of northern European descent. Genetic linkage and linkage disequilibrium studies indicate that the disease locus is tightly linked to HLA-A and D6S105. Recombination between HFE and HLA class I loci is known to be rare. We report here two pedigrees in which recombinations telomeric of HLA-A occurred. These recombinant events define new centromeric and telomeric borders for the HFE locus.

(f Med Genet 1997;34:28-33)
\end{abstract}

Keywords: haemochromatosis; recombination; borders.

Hereditary haemochromatosis (HFE) is inherited as an autosomal recessive trait and is characterised by malregulation of intestinal iron absorption. The inability to regulate absorption of dietary iron properly eventually leads to iron overload and damage to the liver, heart, endocrine glands, and joints. Little is known about the mechanism and regulation of iron absorption by the enterocyte. Consequently, there are no obvious functional candidates for the haemochromatosis gene product and attempts to identify the HFE gene have relied upon positional cloning strategies.

The HFE locus is linked to the class I region of the human major histocompatibility complex (MHC) on the short arm of chromosome 6 .

until recently, few polymorphic markers had been mapped telomeric of the class I region. We report two pedigrees in which recombinations have occurred telomeric of HLA-F and define a centromeric boundary at locus D6S105 and a telomeric boundary for the HFE locus at marker D6S1545.

\section{Materials and methods}

EXPERIMENTAL SUBJECTS

All participants gave verbal and written informed consent. All procedures used were reviewed and approved by the University of Utah Institutional Review Board and the Clinical Research Center Advisory Committee of the University of Utah. People were considered to express the HFE phenotype if they met one or more of the following criteria: transferrin saturation greater than $62 \%$ for men and greater than $50 \%$ for women; an unexplained rise of serum ferritin concentration greater than $325 \mathrm{ng} / \mathrm{ml}$ for men and greater than $125 \mathrm{ng} / \mathrm{ml}$ for women; hepatic parenchymal stainable iron grade 2-4 (normal 0-1); a raised hepatic iron concentration greater than $140 \mu \mathrm{g}$ iron per $100 \mathrm{mg}$ liver dry weight. ${ }^{1213}$ Sibs who were HLA identical to a proband were evaluated with the same tests as the probands.

\section{CLINICAL EVALUATION}

Participating relatives underwent measurement of serum iron concentration, percent saturation of transferrin, and serum ferritin concentration. Hepatic storage iron was assessed by a microscopic grading method and by atomic absorption spectroscopy. Liver tissue was stained for iron using Perl's reagent. The hepatic parenchymal cell stainable iron was determined as described earlier. ${ }^{12}$ fined. Simon et a ${ }^{\beta}$ suggested that the original HFE mutation occurred on a chromosome bearing the haplotype A3, B7. Furthermore, haplotype analyses strongly support the notion for an HFE founder chromosome. ${ }^{45}$ Linkage disequilibrium analyses indicate a broad candidate region for the HFE locus beginning approximately $100 \mathrm{~kb}$ centromeric of HLA-A and extending nearly $3 \mathrm{Mb}$ telomeric. ${ }^{6-9}$ The location of disequilibrium peaks has differed in different populations and peak values have not been strong enough to define a narrow region for the HFE locus.

Borders for the HFE locus as defined by recombinations have been limited by two factors. First, recombination between $\mathrm{HFE}$ and markers in the class I region is rare. ${ }^{10}{ }^{11}$ Second,

\section{DNA SAMPLES AND MARKERS}

HLA assignments were made using standard serological assays. DNA was isolated from peripheral blood lymphocytes using previously described methods. ${ }^{14}$ Alleles for the molecular markers were determined by PCR amplification followed by electrophoresis on sequencing gels. Both radioactive and fluorescent labelling methods were used. The microsatellite markers analysed were D6S265, 306, 464, 105, 299, and $461,{ }^{15}$ D6S1260, ${ }^{9}$ D6S1558, GATAp19326, D6S1545, and D6S1691, ${ }^{16}$ AFM207wh2 and AFMa223xd9. ${ }^{17}$ PCR con- 
Centromere

Telomere

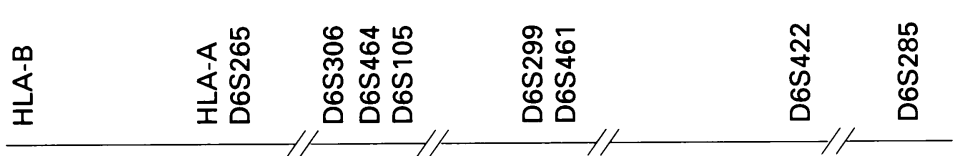

$\longmapsto$
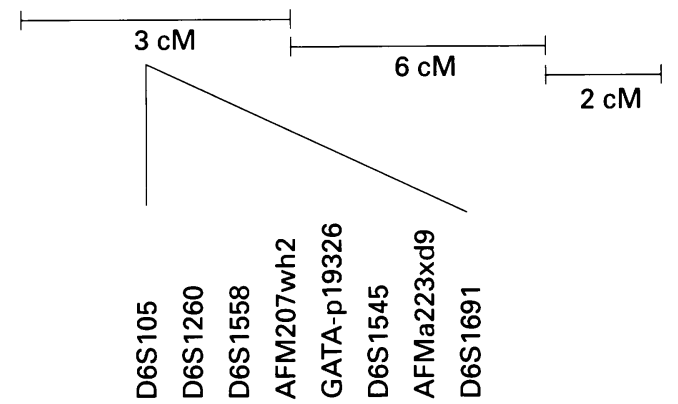

Figure 1 Polymorphic markers used for haplotyping in recombinant pedigrees. Double slashes denote regions where the horizontal line does not reflect physical distance. For markers spanning D6S105-D6S1691, the order is known, but physical distances have not been determined. Genetic distances are according to Gyapay et al. ${ }^{15}$

ditions were as follows: $100 \mathrm{ng}$ template, $10 \mathrm{mmol} / \mathrm{l} \mathrm{Tris}-\mathrm{HCl}(\mathrm{pH} 8.3), 40 \mathrm{mmol} / 1 \mathrm{NaCl}$, $200 \mu \mathrm{mol} / 1$ each $\mathrm{dNTP}, 0.5 \mu \mathrm{mol} / 1$ each primer, $1.25-1.5 \mathrm{mmol} / 1 \quad \mathrm{MgCl}_{2}, 0.25 \mathrm{U}$ Taq poly- merase, $0.2 \mathrm{mmol} / 1$ spermidine $\mathrm{HCl}$, in a $20 \mu \mathrm{l}$ reaction volume. After an initial $94^{\circ} \mathrm{C}$ denaturation step, PCR cycles were as follows: $56^{\circ}-66^{\circ} \mathrm{C}$ (depending on primer set) 20 seconds, step down $1^{\circ} \mathrm{C}$ per cycle to $48^{\circ}-62^{\circ} \mathrm{C}$, then 30 cycles.

\section{HAPLOTYPE ANALYSIS}

Haplotypes were constructed by pedigree analysis. Controls were selected from spouses marrying into our pedigrees, pedigree members sharing no HLA haplotype in common with the proband, or family members whose genotype could be confirmed within the pedigree. All controls had normal values for percent saturation of transferrin and for serum ferritin concentration.

\section{Results}

GENETIC MARKERS

Polymorphic markers extending from HLA-B to D6S285 were used for recombinant screening and haplotyping (fig 1 ). The markers span a genetic distance of approximately $13 \mathrm{cM} .{ }^{15}$ HLA-A and -B alleles were determined by

Table 1 Pedigrees displaying evidence of recombination

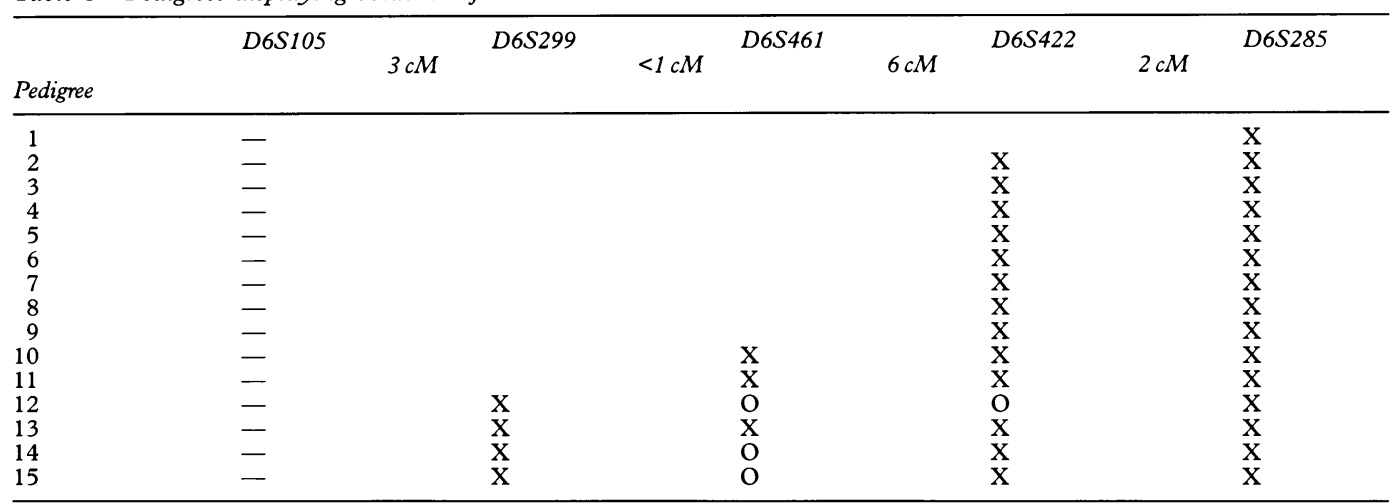

$\mathrm{X}$ indicates evidence of recombination. $\mathrm{O}$ indicates uninformative genotype. - indicates no evidence of recombination. Estimated genetic distances are displayed in centimorgan units.

Table 2 Clinical data for recombinant pedigrees

\begin{tabular}{|c|c|c|c|c|c|c|c|c|c|}
\hline Patient & Age & Sex & $\begin{array}{l}\text { Serum } F e \\
(\mu g / d l)\end{array}$ & $\begin{array}{l}\text { Tf sat } \\
(\%)\end{array}$ & $\begin{array}{l}\text { Serum ferritin } \\
(\mathrm{ng} / \mathrm{ml})\end{array}$ & $\begin{array}{l}H P C S I \\
(0-4)^{*}\end{array}$ & Fibrosis & $\begin{array}{l}H I C \\
(\mu g / 100 \mathrm{mg})^{*}\end{array}$ & $\begin{array}{l}\text { Mobil } \\
\mathrm{Fe}(g)^{*}\end{array}$ \\
\hline $\begin{array}{l}\text { Normalt } \\
\text { Pedigree } 15\end{array}$ & & & $<170$ & $<60(M)$ & $<325$ (M) & $0-1$ & & $<140$ & \\
\hline $\begin{array}{c}\text { Pedigree } 15 \\
\text { I.1 }\end{array}$ & 55 & $\mathrm{~F}$ & 90 & $\begin{array}{r}<50 \\
25\end{array}(\mathrm{~F})$ & & nd & & & \\
\hline & & & & 10 & 113 & na & nd & nd & nd \\
\hline I. 3 & 48 & $M$ & $\begin{array}{r}90 \\
220\end{array}$ & 18 & 34 & nd & nd & nd & nd \\
\hline & 44 & $\mathrm{M}$ & 222 & 100 & 847 & 4 & yes & nd & 15.8 \\
\hline II. 1 & 22 & $F$ & 153 & 53 & 73 & nd & nd & nd & nd \\
\hline II. 3 & 17 & $\mathrm{~F}$ & 129 & 63 & 169 & 2 & no & 750 & 3.4 \\
\hline & 17 & $M$ & 195 & 100 & 546 & 4 & no & 1182 & nd \\
\hline \multirow{2}{*}{\multicolumn{10}{|c|}{ Pedigree 13}} \\
\hline & & & & & & & & & \\
\hline II. 2 & 41 & N1 & 233 & 96 & 2955 & 4 & yes & 2867 & 14.2 \\
\hline II. 3 & $\begin{array}{l}41 \\
40\end{array}$ & F & 114 & 30 & 13 & nd & nd & nd & nd \\
\hline II. 4 & 39 & $M$ & 135 & 39 & 208 & 1 & no & 119 & nd \\
\hline II. 5 & 39 & $\mathrm{~F}$ & 63 & 13 & 2 & nd & nd & nd & nd \\
\hline II. 6 & 37 & $M$ & 219 & 50 & 157 & nd & nd & nd & nd \\
\hline & 34 & $M$ & 150 & 39 & 87 & nd & nd & nd & nd \\
\hline III. 1 & 38 & $\mathrm{~F}$ & 81 & 22 & 15 & nd & nd & nd & nd \\
\hline III. 2 & 19 & F & 144 & 35 & 17 & nd & nd & nd & nd \\
\hline III. 3 & 16 & $M$ & 99 & 20 & 9 & nd & nd & nd & nd \\
\hline III. 3 & 21 & M & 192 & 41 & 26 & nd & nd & nd & nd \\
\hline III. 4 & 13 & M & 46 & 21 & 10 & nd & nd & nd & nd \\
\hline III. 5 & 16 & 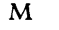 & 123 & 31 & 42 & nd & nd & nd & nd \\
\hline
\end{tabular}

*Abbreviations: HPCSI = hepatic parenchymal cell stainable iron. $\mathrm{HIC}=$ hepatic iron concentration $(\mu \mathrm{g} / 100 \mathrm{mg}$ liver dry weight $) . \mathrm{Mobil} \mathrm{Fe}=\mathrm{mobilisable}$ iron in grams. $\quad$ A

† Normal values are shown in bold. $\mathrm{nd}=$ not determined. 


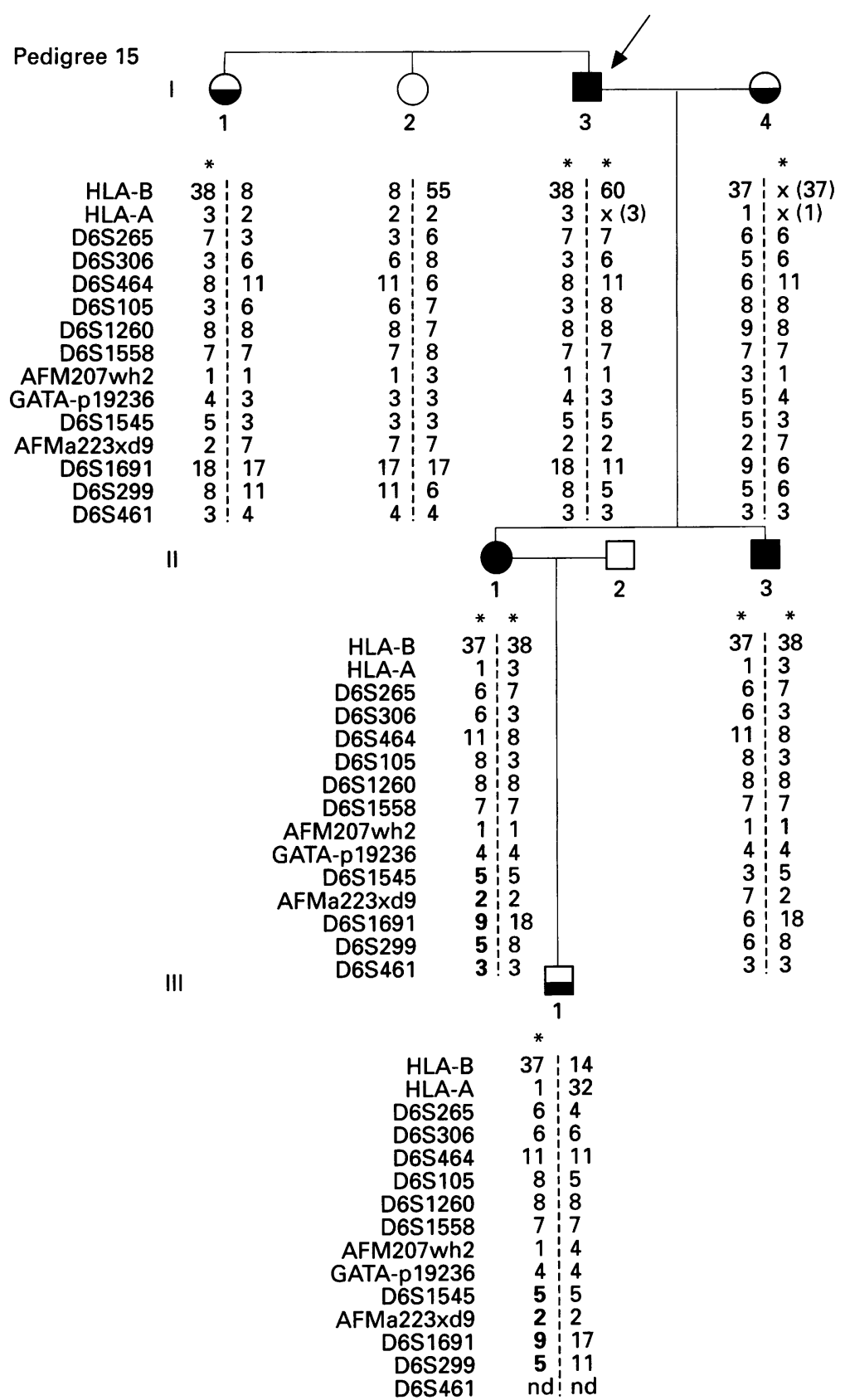

Figure 2 Pedigree showing a recombination which defines a telomeric boundary for the HFE locus. Affected chromosomes are denoted by an asterisk. The recombined portion of the chromosome shows alleles in bold. nd=not determined. The arrow indicates the proband. bolism. ${ }^{18}$ To avoid the problem of variable penetrance we first sought evidence of recombinations telomeric of HLA-A in HLA identical, affected sibs. Sib sets from 59 pedigrees were screened for recombinations by genotyping at telomeric loci. Locus D6S285 is approximately $11 \mathrm{cM}$ telomeric of D6S105 (fig 1) and 15 cases from 151 subjects analysed displayed different genotypes at this locus. This group was then screened using markers extending centromeric towards the class I region. A summary of these data is shown in table 1 .

HAPLOTYPING IN SPECIFIC PEDIGREES

Pedigrees 12 to 15 had affected, HLA identical sib pairs with different genotypes at locus D6S299. These pedigrees were then haplotyped using the more centromeric polymorphic markers described earlier (fig 1). Pedigrees 13 and 15 were of particular interest because the recombination extended centromeric of D6S299. In pedigree 15, subjects II. 1 and II.3 are HLA identical, clinically affected (table 2 ), and recombinant between markers GATAp19326 and D6S1545 (fig 2). The recombination is confirmed in III.1. Because the affected phenotype was not lost in the recombination, the HFE locus must be centromeric of D6S1545.

A different situation was found in pedigree 13 (fig 3). Haemochromatosis in subject II.1 was first detected in 1988 at the age of 39 . He sought medical attention because of fatigue, epigastric pain, and arthralgias. He had no known relative with haemochromatosis. Abnormal physical findings included grey skin pigmentation and hepatomegaly. Laboratory studies showed a raised serum iron concentration $(233 \mu \mathrm{g} / \mathrm{dl})$, a transferrin saturation of $96 \%$, a serum ferritin concentration of $2955 \mathrm{ng} / \mathrm{ml}$, and a hepatic iron concentration of $2867 \mu \mathrm{g} / 100 \mathrm{mg}$ liver, dry weight. The diagnosis of haemochromatosis was confirmed by percutaneous needle biopsy of the liver, which showed grade 4 hepatic parenchymal cell stainable iron and hepatic fibrosis. Seventy-one phlebotomies ( $500 \mathrm{ml}$ each), performed once weekly, were required to produce iron limited erythropoiesis and to reduce the serum ferritin concentration to $18 \mathrm{ng} / \mathrm{ml}$. Phlebotomies continue to be done at three monthly intervals. In the autumn of 1995 , the serum ferritin was $32 \mathrm{ng} / \mathrm{ml}$, the serum iron $249 \mu \mathrm{g} / \mathrm{dl}$, and the transferrin saturation $65 \%$.

The HLA identical brother of the proband (II.3) is younger by one year and was evaluated as part of a pedigree analysis. Although he was clinically well, he was initially assumed to be affected, based on HLA identity to the proband. His physical examination was normal. Iron studies showed a serum iron of $135 \mu \mathrm{g} / \mathrm{dl}$, a transferrin saturation of $39 \%$, and a serum ferritin concentration of $208 \mathrm{ng} / \mathrm{ml}$, all normal values. A liver biopsy showed no increase in hepatic iron (hepatic parenchymal cell stainable iron grade 1), hepatic iron concentration $119 \mu \mathrm{g} / 100 \mathrm{mg}$ dry weight, and no evidence of fibrosis. Subject II. 3 has been evaluated on a regular basis for the last eight years. Serum 


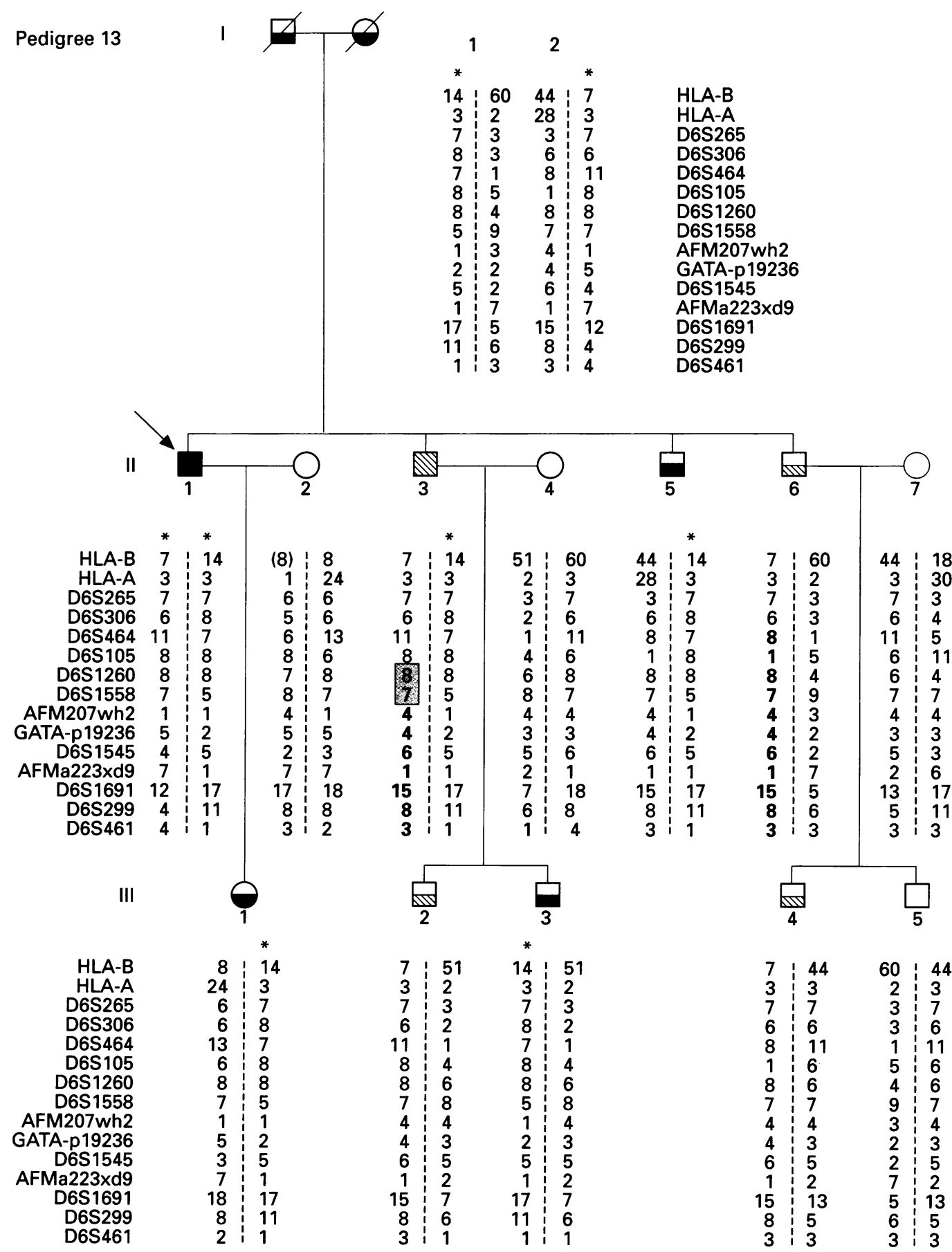

Figure 3 Pedigree showing a recombination defining a centromeric border for the HFE locus. Asterisk denotes affected chromosome. Alleles from the recombined chromosome are shown in bold. Hatched areas indicate carrier allele suggested by $H L A$ serotype. The parents in this pedigree are dead and parental haplotypes are inferred. The shaded box represents markers which might be included in the recombinant region, but parental haplotypes are uninformative. The arrow indicates the proband.

iron determinations have ranged from $135 \mu \mathrm{g} /$ dl to $189 \mu \mathrm{g} / \mathrm{dl}$. Serum transferrin saturations have ranged from $39 \%$ to $53 \%$. Serum ferritin concentrations have ranged from $130 \mathrm{ng} / \mathrm{ml}$ to $208 \mathrm{ng} / \mathrm{ml}$, all normal values for males (table 2). This person remains in good health and no phlebotomies have been performed.

In pedigree 13 the recombination in subject II. 3 begins at locus AFM207wh2. The inferred parental haplotypes (both parents dead) at D6S1558 and D6S1260 are uninformative for the recombined chromosome owing to homozygosity at these loci (fig 3). Inheritance of the recombined chromosome was confirmed in
III.2 and III.4. These results indicate that the HFE allele was lost in the recombination, and places a centromeric boundary for HFE between D6S105 and AFM207wh2. There is also an apparent recombination in II. 6 between D6S306 and D6S464. The recombined chromosome was inherited by III.4. Neither II 6 nor III.4 show any clinical evidence of iron overload.

\section{Discussion}

Linkage between HFE and HLA-A3 is well documented and HLA-A has served as a land- 
mark in attempts to localise the disease locus. The strong allelic association is because of a founder effect, and ancestral haplotypes for the HLA-A3 HFE chromosome have been reported previously. ${ }^{45}$ Linkage disequilibrium methods have been used to narrow the region containing the HFE locus. These analyses indicated that an unusually large region, extending over $3 \mathrm{Mb}$ from HLA-A to D6S1260, is in significant disequilibrium with $\mathrm{HFE}$, but no unequivocal peak of linkage disequilibrium has been defined. ${ }^{48919}$

Several factors might explain such a broad region of disequilibrium. First, any phenomenon which reduces recombination would preserve the ancestral haplotype. A recent report compared physical and genetic distances in the human MHC. The estimated genetic distance of the class I region was approximately one third that expected based on comparisons of genetic versus physical distances in the class II and III regions. ${ }^{20}$ This apparent suppression of recombination may extend into the telomeric flanking regions. Second, the HLA-A3 associated HFE mutation may have occurred quite recently and the founder chromosome may not yet have had enough time to undergo significant recombination. ${ }^{21}$ Under these conditions, allelic associations would be preserved, resulting in a broad region of linkage disequilibrium. A relatively recent founder HFE mutation would also make disequilibrium analysis very sensitive to population differences and may explain discrepancies in reported disequilibrium peaks. Although disequilibrium analysis has been useful in identifying other disease loci, ${ }^{22-24}$ the lack of a single, strong disequilibrium peak limits its use in localising the HFE locus.

Recombinations within pedigrees have been used to define borders for disease loci. Recombinations between HFE and class I markers are rare and HLA identity to an affected sib has been a reasonable predictor for the disease genotype. A recombination in the region centromeric of HLA-A has already been identified and mapped between HLA-E and $-C .{ }^{10}$ The recent development of polymorphic markers telomeric of the class I region permitted us to define a new centromeric border at locus D6S105 for the HFE candidate region. We therefore concentrated on the markers distal to HLA-A in order to define a telomeric border for the HFE candidate region.

The clinically unaffected sib in pedigree 13 (II.3) has been carefully followed for eight years. No disease has been identified that might have caused iron loss. The caveat of incomplete penetrance remains but this has not been known to occur in males. ${ }^{18}$ The molecular evidence for recombination in II. 3 suggests that the crossover resulted in loss of the disease allele. Possible recombinations resulting in a similar situation have been reported previously but the crossover points have not been described. ${ }^{25}$ We can assign a centromeric boundary between D6S105 and AFM207wh2, but the intervening markers were uninformative owing to homozygosity at these loci in the parental chromosomes.
Our assignment of a telomeric border between D6S1545 and GATA-p19326 seems clear as the crossover occurred in a person who clearly retained the homozygous HFE phenotype (II.1, fig 2, table 2). Additional recombinant pedigrees are being sought to define new borders for the HFE locus. This is feasible because of the many new polymorphic markers being mapped telomeric of the class I region. A recombination placing the HFE locus telomeric of HLA-F has been reported ${ }^{11}$ but our data move the centromeric boundary to a region distal to D6S105. As more informative markers are developed and mapped in this region, the candidate region should be narrowed further.

The authors thank Diana Dimitrova and Jalene Barrow for excellent technical assistance. Drs J Kaplan and C Perou provided helpful comments and discussion. RSA and JPK were supported by NIH DK-20630. JRG was supported in part by supported by NIH DK-20630. JRG was supported in part by Some Some genotyping was performed in the Genomics Core Facility of the Huntsman Cancer Institute. Patient samples were collected in the Clinical Research Center at the University of Utah

1 Simon $M$, Bourel $M$, Fauchet $R$, Genetet B. Association of HLA-A3 and HLA-B14 antigens with idiopathic haemochromatosis. Gut 1976;17:332-4.

2 Cartwright GE, Skolnick M, Amos DB, Edwards CQ, Kravitz $\mathrm{K}$, Johnson, A. Inheritance of hemochromatosis: linkage to HLA. Trans Assoc Am Physicians 1978;91:273-81.

3 Simon M, LeMignon L, Fauchet R, et al. A study of 609 HLA haplotypes marking for the hemochromatosis gene: (1) mapping of the gene near the HLA-A locus and haracters required to define a heterozygous population and (2) hypothesis concerning the underlying cause of hemochromatosis-HLA association. Am f Hum Genet 1987;41:89-105.

4 Jazwinska EC, Pyper WR, Burt MJ, et al. Haplotype analysis in Australian hemochromatosis patients: evidence for a predominant ancestral haplotype exclusively associated with hemochromatosis. Am F Hum Genet 1995;56:428-33.

5 Raha-Chowdhury R, Bowen JD, Burnett AK, Worwood M. Allelic associations and homozygosity at loci from HLAB to D6S299 in genetic haemochromatosis. F Med Genet B to D6S299 in

6 Jazwinska EC, Lee SC, Webb SI, Halliday JW, Powell LW. Localization of the hemochromatosis gene close to D6S105. Am ₹ Hum Genet 1993;53:347-52.

7 Worwood M, Raha-Chowdhury R, Dorak MT, Darke C, Bowen DJ, Burnett AK. Alleles at D6S265 and D6S105 define a haemochromatosis-specific genotype. $\mathrm{Br} f$ Haematol 1994;86:863-6.

8 Yaouanq J, Perichon $M$, Chorney $M$, et al. Anonymous marker loci within $400 \mathrm{~kb}$ of HLA-A generate haplotypes in linkage disequilibrium with the hemochromatosis gene (HFE). Am F Hum Genet 1994;54:252-63.

9 Raha-Chowdhury R, Bowen DJ, Stone C, et al. New polymorphic microsatellite markers place the haemochromatosis gene telomeric of D6S105. Hum Mol Genet 1995;4:1869-74.

10 Radisky ES, Ajioka RS, Edwards CQ, Griffen LM, Kushner JP. Mapping recombinant events with molecular markers in hemochromatosis pedigrees. Cytogenet Cell Genet 1994; 67:126-8.

11 Calandro LM, Sensebaugh GF. Characterization of a recombinant that locates the hereditary hemochromatosis combinant that locates the hereditary hemochromatosi

12 Edwards CQ, Carroll M, Bray P, Cartwright GE. Hereditary hemochromatosis: diagnosis in siblings and children. $N$ Engl f Med 1977;297:7-13.

13 Edwards CO, Dadone MM, Skolnick MH, Kushner JP. Hereditary hemochromatosis. Clin Haematol 1982;11:41135.

14 Bell G, Karam JH, Rutter WJ. Polymorphic DNA region adjacent to the $5^{\prime}$ end of the human insulin gene. Proc Natl Acad Sci USA 1981;78:5759-63.

15 Gyapay G, Morissette J, Vignal A, et al. The 1993-94 Genethon human genetic linkage map. Nat Genet 1994, 7:246-339.

16 Whitehead Institute data base: http://www-genome.wi mit.edu/

17 Bray-Ward P, Bowlus C, Choi J, et al. FISH-mapped CEPH YACs spanning 0 to $46 \mathrm{cM}$ on human chromosome 6 . (Submitted.)

18 Edwards CO Griffen LM, Goldgar D, Drummond C Skolnick MH, Kushner JP. Prevalence of hemochromatosis among 11,065 presumably healthy blood donors. $N$ Engl f Med 1988;318:1355-62.

19 Stone C, Pointon JJ, Jazwinska EC, et al. Isolation of CA dinucleotide repeats close to D6S105; linkage disequilibrium with haemochromatosis. Hum Mol Genet 1994;3:2043-6.

20 Martin M, Mandd D, Carrington M. Recombination rate across the HLA complex: use of microsatellites as a rapid 
screen for recombinant chromosomes. Hum Mol Genet 1995;4:423-8.

21 Ajioka RS, Jorde LB, Gruen JR, et al. Haplotype analysis of hemochromatosis chromosomes: localization based on linkage disequilibrium and evolution of disease chromosomes. (Submitted.)

22 Hegele RA, Plaetke R, Lalouel JM. Linkage disequilibrium between DNA markers at the low-density lipoprotein

23 Jorde LB, Watkins WS, Viskochil D, O'Connell P, Ward K.
Linkage disequilibrium in the neurofibromatosis 1 region: implications for gene mapping. Am $\mathcal{F}$ Hum Genet 1993;

24 Jorde LB, Watkins WS, Carlson M, et al. Linkage disequilibrium predicts physical distance in the adenomatous polyposis coli region. Am f Hum Genet 1994;54:884-98.
25 Powell LW, Summers K M, Board P G, Axelsen P, Webb Powell LW, Summers K M, Board P G, Axelsen P, Webb
W, Halliday JW. Expression of hemochromatosis in homozygous subjects. Implications for early diagnosis and prevention. Gastroenterology 1990;98:1625-32. 